\title{
Perceived impact of climate change on crop yield trend in Denbia Woreda of Amhara Region, Northwest Ethiopia
}

\begin{abstract}
Background: The aim of this study was to examine the perceived impact of climate change on crop yield trend in Denbia woreda (district) of Amhara Region, northwest Ethiopia. Systematic random sampling with proportionate representation was used to determine 372 sample sizes from 5362 rural households. Quantitative data on crop production and perception of households to crop yield trend in the past years was collected using structured questionnaire complemented with informants' interview and field observation. Rainfall and temperature records of Gorgora Meteorology Station and Global Weather Data for Soil and Water Assessment Tool (SWAT) in Chuahit area were gathered for 1979 to 2010 . Crop yield data were obtained from North Gondar Zone Agriculture Department Office. Simple linear regression (SLR), standardized precipitation index (SPI), one-way-analysis of variance (ANOVA), standard deviation, and index of trend of yield (ITY) complemented with descriptive statistics were used to analyze the quantitative data.
\end{abstract}

Results: The results show increasing temperature and decreasing rainfall amount, increasing unpredictability, and fluctuation of rainfall, consistent with households' perception towards temperature, rainfall and crop yield tendencies. Farmers' perceptions demonstrate the negative impacts of climate trends on crop yields at local scale. Very low crop yield, particularly in the flood-prone areas were reported due to geographic exposure to recurrent flooding and deposition. In fact, the crop yield indices reveal the negative trend with and index value of $(-0.80)$, indicating that crop yield is going down in the past years against the official agricultural statistics.

Conclusion: This study recommends context-specific solutions to enhance crop productivity. Local leaders should enforce green laws by encouraging peoples' tree plantation that enable to regulate the local climate through carbon sequestration and reducing flood risks of heavy rainfall events. In this regard, research should be conducted on the reproduction of heat and flood-tolerant crop varieties in the study area. Further research is needed to settle deviations of official crop yield statistics from households' perceptions to crop yield trend.

Keywords: analysis of variance, climate change, crop yield, Denbia, Ethiopia, index of trend of yield
Volume 2 Issue 7 - 2017

\section{Menberu Teshome}

Department of Geography and Environmental Studies, Debre Tabor University, Ethiopia

Correspondence: Menberu Teshome, Ph.D, Department of Geography and Environmental Studies, Debre Tabor University, Ethiopia, Po Box 272,

Email menberuteshome@gmail.com, menberuteshome@dtu. edu.et

Received: September 06, 2017 | Published: November 22, 2017

\section{Introduction}

The most distressful event by posing tremendous negative impact on several sectors of the world is climate change ${ }^{1}$ which is defined as a statistically significant variation in either the mean state of the climate or in its variability, persisting for an extended period (typically decades or longer) (McCarthy et al. 2001). Annual global temperatures have increased by $0.4{ }^{\circ} \mathrm{C}$ since 1980 , with even larger changes observed in several regions. ${ }^{2}$ After the Industrial Revolution, human-induced climate change has added new unpredictable threats to societies due to not only the occurrence of extreme weather events but also for failures to adequately address pervasive poverty ${ }^{3}$ and severe land degradations. ${ }^{4,5}$ The negative impact of climate change has been reported on all aspects of freshwater, ecosystem, biodiversity, food security, and safety and nutritional quality of human beings. ${ }^{5}$ Climate change adversely affects the biophysical and socio-economic resources and hence it is considered to be one of the most serious threats to sustainable development endeavors and will continue so in the decades to come for both developed and developing world (Houghton et al., 2001). The impact is more severe in the developing countries where agriculture is the foundation of the economy and societal well-being. In fact, human welfare depends to a large extent on the amount and stability of agricultural production as determined by climatic conditions because agriculture occupies $40 \%$ of the land surface, consumes $70 \%$ of global water resources and exploits huge biodiversity resources for various purposes. Agriculture is the most susceptible sector to climate change related hazards due to the fact that climate change affects the two most important direct agricultural production inputs: precipitation and temperature. ${ }^{6}$ Rainfall and temperature have posed tremendous impact on crop yields of the agrarian communities of the developing countries like Ethiopia where agriculture is rain-fed and essential for the daily subsistence. ${ }^{5,7}$ Anticipated changes in climate are expected to have large and farreaching effects, mainly in the tropical zones of the developing world where precipitation regimes range from semiarid to humid areas. ${ }^{8}$ Hazards such as excessive heat conditions, greater frequency and severity of drought in semi-arid areas and increased flooding in lowlying areas, all can limit crop growth and expected crop yields. ${ }^{1}$ Africa is one of the most vulnerable continents to climate change-induced risks because of its geographic exposure, low incomes, heavy reliance on agriculture and limited capacity to seek alternative sources of livelihood. It is projected that by the 2050s, 350-600 million Africans 
will be at risk of increased water stress and very low agricultural production. In the light of this, about 60 to 90 million hectares of land will be changed into arid and semi-arid land by 2080s; up to $50 \%$ agricultural yield decline is likely due to drought and severe land degradation; and an increase in run-off is projected in East Africa where Ethiopia is situated by the 2050s. ${ }^{1,2}$ Ethiopia is situated in the horn of Africa where environmental change has critical implications for agriculture, water, health, and forestry. The country is among the most vulnerable nations to climate and ecological changes, given that only a small proportion of its cultivated land is irrigated and food production is highly dependent on traditional rain-fed agriculture (crop production and livestock keeping). ${ }^{9}$ Rain-fed agriculture is very sensitive to climatic fluctuations and to aggravate poverty in the country. ${ }^{10}$

Crop production is the dominant livelihood base of the people of Amhara region like elsewhere in Ethiopia. Over $85 \%$ of the active population is engaged in this sector. However, north and northeast parts of the region are more exposed to shortage of rainfall with receiving less than $700 \mathrm{~mm}$ annually ${ }^{11}$ and shortage of food throughout the year. Many surplus producing woredas (districts) before two decades in North and South Gondar, East Gojjam and North Shewa administrative zones have already become highly vulnerable to food insecurity and poverty. ${ }^{12,13}$ Denbia woreda is located in the northwest part of Ethiopia where the localized temporal rainfall and temperature variability during cropping season induces the main challenges to crop production through flooding, insect outbreak, spreading of alien weeds, disease, and pests. ${ }^{14}$ This situation calls for scientific investigations which would enable to design local specific intervention and help to improve the communities' adaptive capacity against the present and future challenges of climate change-related hazards. Many studies have shown that climate change has adverse impacts on human welfare, natural resources and development activities in Ethiopia in general and Amhara Regional State in particular. ${ }^{15,16}$ While many studies have considered the impact of climate change on food production, the effects of these past changes on agriculture remain unclear. It is likely that warming has improved yields (food production per unit of land area) in some areas, reduced them in others and still had negligible impacts in others. In addition, most of the previous studies were carried out at macro-levels aggregated at State and national levels. However, unless, the effects of climate variability are known and understood at the micro-level by the local people through establishing the right perception, it would be difficult to convince and motivate local leaders and communities to undertake mitigation and adaptation actions. Moreover, the previous studies greatly focused on technology development without considering climate variability and change. Although recurrent weather-related extreme events have fueled new avenues of inquiry to know and address human and social vulnerability to these events in a wider geographical scope in recent times, context-specific studies on perceived impact of climate change on crop yield trend, remains scant. This study, therefore, examined the perceived impact of climate change on crop yield trend over the past years in Denbia woreda of Amhara region, Northwest Ethiopia.

\section{Study area}

This study was conducted in Denbia woreda of North Gondar Administrative Zone. North Gondar is an administrative Zone in the Ethiopian Amhara Region. This Zone is named for the city of Gondar, the capital of Ethiopia until the mid-19 $9^{\text {th }}$ Century. North Gondar is bordered in the south by Lake Tana, West Gojjam, AgewAwi and Benishangul-Gumuz Region, in the west by Sudan, in the north by Tigray Region, in the east by Wag-Hemera zone and in the southeast by South Gondar. Part of the North Gondar zone, Denbia is bordered by Lake Tana in the south, Takussa woreda in the southwest, Chilga in the west, Lay Armachiho in the north, and Gondar zuria woreda in the east (Figure1). The woreda capital, Koladiba, is located $750 \mathrm{Km}$ North of Addis Ababa and $35 \mathrm{~km}$ away from Gondar City. ${ }^{17}$ The woreda is mainly woyna-dega (midland) in terms of agroecological setting with elevation ranging from 1700 to $2600 \mathrm{~m}$ above sea level. The topography of the area is dominated by plain (flat terrain $(87 \%)$. The rest is characterized by mountainous landscape $(5 \%)$, valleys $(4.8 \%)$ and wetland $(3.2 \%)$. Out of the total area of the woreda, $32.97 \%$ is being used for annual crop production, $12.75 \%$ for grazing, $5.65 \%$ for forest development, bush and shrubs, 15.95 $\%$ is degraded (unproductive) land and the residential areas constitute about $4.37 \% .{ }^{14}$ The average landholding size of the households for crop production is 0.87 hectare in the woreda. The area is endowed with potential perennial and seasonal water resources for small-scale irrigation. The data obtained from the woreda Agriculture Office (2013) indicate that a total of 3051 hectares of farmland is being cultivated with traditional irrigation, from which only 80 hectares of farmland is cultivated under modern irrigation systems. Flood-plains and wetlands around Lake Tana also characterize Denbia woreda which is entirely located in the Tana growth corridor livelihood zone with relatively good potential for agricultural production (Woreda Office of Agriculture 2012). However, recent climate change and associated extreme weather events are having a significant and new impact. Moreover, the land is devoid of vegetation cover due to uncontrolled deforestation for agriculture, fuel and construction purposes that results in serious soil erosion in the hilly areas and deposition over the low-lying areas of Lake Tana. Soil degradation is being further accelerated by removing topsoil from cultivated lands and causing agricultural productivity to go down from time to time. Undoubtedly, the acceleration of environmental degradation and climate changeinduced flooding, erratic and untimely rainfall, snowfalls, crop pests and disease, livestock disease, malaria and other human diseases, and small size landholdings among other factors have direct effects on crop yield and food security of thousands of people living in poverty in the woreda. ${ }^{17-19}$

\section{Research methods}

\section{Sampling techniques}

Denbia woreda was purposely selected for this study by considering its high vulnerability conditions to flood, disease (human, animal and crop), and crop pests due to its location in the low laying areas of Lake Tana. And then, four kebele administrations (KAs) (the lowest administrative units in Ethiopia), namely Gerarge, Jenda-kobla, Seraba-dablo and Tana-woyna, were selected using simple random sampling technique. Sample size (372 households) was determined for each KA using probability proportional to size (PPS) method to make equal representation of households in each kebele based on Israel [20]. Systematic random sampling technique was used to select sample rural households. In the process, sampling frames (the list of all household heads), were taken from each kebele offices. The sample households were drawn for each KA from the list of names after a certain sampling interval $(\mathrm{K})$ that was determined by dividing the total number of households by the predetermined sample size of each kebele. Next, a number was selected between one and the sampling interval $(\mathrm{K})$ which is called the random start using lottery method and was used as the first number included in the sample. Then, every Kth household head after that first random start was taken until reaching the desired sample size for each KA. ${ }^{20}$ 


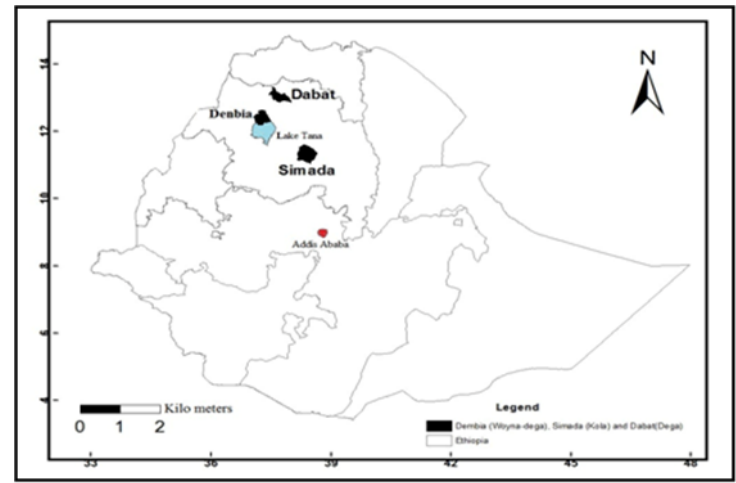

Figure I Location Map of Denbia Woreda.

\section{Methods of data collection}

This study used a survey design in order to assess impacts of climate change on crop yields of local people in Denbia woreda of north Gondar zone, Amhara Region, northwest Ethiopia. Therefore, to accomplish the proposed research with respect to the nature of the research objectives, a combination of quantitative and qualitative data collection and analytical techniques were employed. Both secondary and primary data sources were used in the study.

\section{Secondary data}

To examine the impacts of climate change on crop production, crop yield data with climatic parameters (such as temperature and rainfall) were gathered and employed. The 32 years meteorology data (rainfall, maximum temperature and minimum temperature) were gathered from Gorgora Meteorology Station and Global Weather Data for Soil and Water Assessment Tool (http://globalweather.tamu. edu) at Chuahit area for the period 1979 to 2010. Using these data temperature and rainfall trends and drought duration, magnitude and intensity were analyzed. The choice of these three climatic parameters was based on their powerful role on agricultural sector while yield data for teff, wheat, barley, maize, sorghum, and millet were obtained from North Gondar Administrative Zone Agricultural Development Office (NGZADO)

Primary data: The data obtained from secondary sources include only meteorology records and kebele population size which were found to be insufficient to achieve the intended research objectives. Therefore, the primary data collection methods were determined to be the major data sources for this paper. Hence, primary data were collected using household survey, key informant interview and field observation for the successful completion of the study.

Household survey: The household survey was used to collect a range of quantitative data on farmland location and exposure to flood and perception of farming households to climate change and variability as well as crop yield trend over the past 20 years or so. The survey questions were organized mostly into close-ended and open-ended forms. The data sets are very important to calculate index of crop yield trend; analyzing productivity variance among the four selected kebele administrations (KAs), and computing frequency distribution, percentage, maximum and minimum values of the observation. Perception is a prerequisite for adaptation. Thus, perception to climate change was analyzed based on the farming households' observations of the surrounding environment. The survey raised questions about the farming households' observations to the patterns of temperature over the past two or more decades. Responses to the questions about whether the farming household had witnessed changes in temperature were classified into one or more of three different categories: 'increased', 'decreased' and 'no change'. In the same fashion, the household survey raised questions about the observations of rural households to the patterns of precipitation over the past two or more decades. Responses to the questions about whether the household had witnessed changes in precipitation were classified into one of the four different categories: 'increased', 'decreased', 'change in timing/erratic in distribution', and 'no change'. The survey questions were prepared and administered in local language - Amharic during the field work and then translated into English during data processing, analysis and interpretations. In order to maintain the validity and reliability of the data, the questions were carefully reviewed by experts working in offices of agriculture, food security and disaster management. As part of validity and reliability check pre-test of questions were made by distributing questionnaires to 10 farmers who were not involved in the actual survey of each site. The pilot survey helped to evaluate whether the instruments were appropriate and suited to the study. Necessary amendments were made through deleting and modifying questions those having confusing and sensitive ideas identified by experts and households. Pre-testing of the questions also helped to determine the mean interview length needed for covering the samples and to plan the time, days and number of data collectors required for the survey. The author trained data collectors on the survey techniques and confidentiality protocol to establish internal quality control procedures. For example, in case survey questions contained ambiguous language that might lead to different answers depending on respondent's interpretation, data collectors were told to have common understanding. Moreover, after the training, the data collectors acquired practical experience while the author made faceto-face interview during the actual data collection in the field. Data collectors were trained to administer the actual household survey with close supervision of the author in the period between April and June 2014. Household heads were approached, but if he/she were not available, the spouses were contacted. When difficulties faced to meet the selected households due to absenteeism (after repeated visits) or unwillingness, the household head listed next to him/her, replaced them. Most of the farmers were contacted on the homesteads and a few of them were consulted on Saturdays, Sundays, and other holidays around churches and community gathering places. The author's former university students had played paramount role in choosing the data collectors who have been working in the community in the areas of agriculture, health and teaching. As they have been living in the community for many years they better know the area and easily approach and handle respondents.

Informant interview: in order to complement and cross-check the data gathered through household survey and secondary sources interviews were held with elders, local authorities, development agents, females, and youth at kebele level and agricultural experts at woreda level. The author identified a total of 12 key informant (KI) interviewees from the four kebele administrations i.e. three from each kebele. This was made to have an overall picture of the kebele administrations and generate general information on the main research problem.

Field observation: direct field observation was conducted to validate the data gathered through household survey. Field observations focused on bio-physical characteristics, land degradation, flood affected areas, water resources and vegetation cover, farming system, cropping pattern and land management practices. Vulnerable areas were documented through photographs by using digital camera. 


\section{Methods of data analysis}

Investigations of climate indicators demand various quantitative and qualitative methods to analyze the quantitative and qualitative data. Descriptive, trend and regression analysis were all used to analyze the quantitative data. Descriptive statistical techniques include mean, maximum, minimum, percentage, standard deviation, median and variance. The trend analysis techniques comprise of simple linear regression, standardized precipitation index (SPI) and index of trend of yield. Inferential statistical technique such as variance (ANOVA) was used to compare crop yield across selected kebele administrations. For examining the perceived impact of climate change on crop yield trend the author first looked at how meteorological data evolved (trend, variability, and drought duration, magnitude, and severity).

Standardized precipitation index (SPI): The SPI was used to identify droughts during the period under consideration using annual rainfall data. The SPI is a statistical measure to detect unusual weather events and then to determine how often droughts of certain strength are likely to occur. The practical implication of SPI-defined drought, the deviation from the normal amount of precipitation, would vary from one year to another. Mathematically, it can be calculated as:

$$
\mathrm{SPI}=\mathrm{X}^{-}-\mathrm{X} \sigma
$$

SPI refers to rainfall anomaly (irregularity) on multiple time scales; $\mathrm{X}$ represents annual rainfall in the year $\mathrm{t}$; the long-term mean rainfall; and $\sigma$ represents the standard deviation over the period of observation (Mckee et al. 1993; Woldeamlak 2009). Hence, the drought severity classes are: extreme drought $(\mathrm{SPI}<-1.65)$; moderate drought $(-0.84>$ SPI $>-1.28)$; severe drought $(-1.28>$ SPI $>-1.65)$; and no drought (SPI $>-0.84)$. Drought duration, magnitude, and intensity were analyzed based on quantified SPI values. Drought duration is the period between drought starts and ends expressed in months or years. Drought magnitude (DM) is the sum of the negative SPI values for all the months or years within the period of drought ${ }^{21}$

\section{Mathematically it can be expressed as: $\mathrm{DM}=\sum \times \mathrm{j}=1-(\mathrm{SPI} \mathrm{ij})[2]$}

Where, $\mathrm{j}$ starts with the first month/year of a drought and continues to increase until the end of the drought (x) for any of the i time scales (the ith month or year from the observation period). Drought intensity (DI) is the ratio of the drought magnitude to the duration event, which can be expressed as DM/DD where DM is drought magnitude and DD is drought duration. Although drought analysis used both the monthly and yearly time scale, the yearly scale was selected for detecting the long-term temporal patterns of drought in the studied area.

One-way Analysis of Variance (ANOVA) was used for comparing the crop yield across the kebele administrations located in different environmental contexts. For examining crop productivity trend the author (of this paper) calculated the average yields of the drought and non-drought years to obtain annual crop yield per hectare for different crops. ${ }^{22}$ Then, the averages of the major crops were considered for analysis. One-way Analysis of Variance (ANOVA) was used to test the mean differences in crop yields that the farmers produce per hectare of farmland under the condition of climate related hazards in the four study sites. The scatter plot presented the mean yield of major crops for individual households for comparing the aggregated mean crop yield among the sampled kebele administrations.

Index of trend of yield: The study also analyzed the stability of crop yield trend by constructing indices of trend of yield (ITY) based on farmers' responses to a question related to detecting productivity trend since the past 20 years or so using the following formula ${ }^{22}$ :

$$
\text { ITY }=\left(\mathrm{fi}^{*} 1+\mathrm{fd}^{*}-1+\mathrm{fc} * 0 / \mathrm{N}\right)
$$

Where, ITY $=$ index of the trend of yield

$f i=$ frequency of responses indicating increasing yield

$\mathrm{fd}=$ frequency of responses indicating decreasing yield

$\mathrm{fc}=$ frequency of responses indicating constant

$\mathrm{N}=$ total number of responses

The quantitative data obtained from the household survey, meteorological records and agricultural development office were processed using Statistical Package for Social Science (SPSS) version 16 and Microsoft Excel 2007. The survey data were inserted into SPSS 16 for processing and analyzing the data using both the descriptive and inferential techniques. In addition, input data for trend analysis, namely frequencies, percentage values and indices of trend of crop yield stability were processed using Microsoft excel sheet for each kebele administration. The quantitative data analysis methods were supported by the qualitative data processing methods. Thus, the qualitative method was used to analyze the information obtained through in-depth interview and field notes written during observations. The collected information was converted into word processing documents in the process of analysis. The author has taken some interviews and observational notes transcribed. Transcription is the process of converting interview, discussion and field notes into text data and then translated from local language (Amharic) to English for narrating and interpreting the issues through answering the 'why' and 'how' questions.

\section{Results and discussion}

Climate change with expected long term changes in rainfall patterns and shifting temperature zones are expected to have negative effects on agriculture. This section presents the major findings and discussions regarding the perceived impact of climate change on crop yield trend in Denbia woreda of Amhara Region, Northwest Ethiopia.

\section{Temperature changes}

In order to detect the trends of both maximum and minimum temperature data of Denbia woreda simple linear trend equation was used. The results show that annual temperature was in an increasing trend for the last three decades (1979-2010). Figure 2 presents the maximum, minimum and average temperature trends of the woreda over the same period. The estimated trend line for average annual temperature is $y=0.042+19.40$. The trend line has a positive slope implying the average temperature is going up by $1.300 \mathrm{C}$ in the past 32 years. On decadal time scales, it rose by $0.410 \mathrm{C}$. It is also found out that the rate of temperature rise in the woreda was found to be faster than the national level temperature increase $(0.230 \mathrm{C}-250 \mathrm{C}$ per decade $)$ over the past 55 years ${ }^{9}$ The maximum and minimum temperature trends were also calculated using simple regression equation for the period. It was found that both of them showed increasing trend in the study area in the observation period. Maximum temperature increased faster while the minimum temperature increased gradually. For example, the former increased by $1.580 \mathrm{C}$ while the later increased by $0.960 \mathrm{C}$ in the past 32 years. In decadal time scale, the maximum temperature rose by $0.490 \mathrm{C}$ and the minimum increased by $0.300 \mathrm{C}$. The analysis of households' observations of their surrounding environment shows that farmers' perceptions appear to be in accordance with the statistical record in the woreda. About $95 \%$ of the surveyed households observed increasing temperature trend over the past 20 years. Only $2 \%$ of the households noticed the contrary and the rest $1.5 \%$ of them have not noticed any temperature change. 
The direction of the temperature trend in the study woreda was found to be consistent with the findings of McSweeney et al. ${ }^{23}$ in Ethiopia, and Menberu ${ }^{18}$ in northwest Ethiopia and Mongi et al..$^{24}$ in Tanzania which found out that those both minimum and maximum temperatures showed increasing trends. However, in Tabora Urban and Uyui Districts of Tanzania minimum temperature increased faster while maximum temperature increased slowly. This increasing temperature trend has adverse effects on water, land and vegetation resources through exacerbating evapo-transpiration with negative effects on the productive capacities of these resources. Inthe light of these, Doering et al. ${ }^{25}$ noted that a continuous rise of temperatures have posed significant impacts on agricultural production. Same author stressed that these impacts are being experienced by many communities in countries of the Southern hemisphere. Increasing drought occurrence and heavy precipitation events also will further cause crop failure, flooding, and soil erosion (Figure 2). On the other hand, this result is quite different from the study conducted in semiarid Tanzania by Mongi et al..$^{24}$ as it pointed out different perceptions among social groups in terms of level of education, location, age and gender. In the case of this study, interview and observation results confirmed that there is no varied understanding on the trends of temperature and rainfall by level of education, age and gender in the study site. In terms of perception, the local communities unanimously agree that the climate is continually changing and getting worse and worse from time to time. In the study site, it is commonly agreed that the temperature is getting much hotter across times. Such a situation results in lamentable crop production and food security efforts.

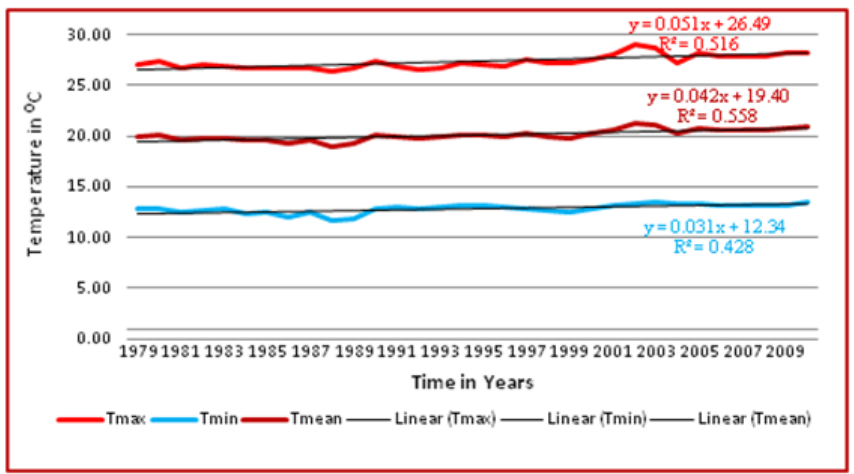

Figure 2 Long-term temperature trends of Denbia woreda (1979-2010).

\section{Rainfall variability and change}

After screening for consistency and completeness of the data, daily rainfall amounts were summed into annual, seasonal and monthly totals. The meteorology data for the period 1979 to 2010 indicate varied rainfall amount and distribution from time to time in Denbia woreda. The total annual rainfall ranges from 870 to $1394 \mathrm{~mm}$. The woreda has experienced uni-modal (Meher) rainfall pattern. The rainfall occurs mostly during the summer season (usually from MidJune to Mid-September), often falling as intense storms causing severe soil erosion (Table 1) \& (Figure 3). Month to month rainfall variability is considerable across the years in the study area. July (11.9267) and August (11.2115) had the highest standard deviation in the study area. The highest amount of average monthly rainfall was also recorded in July $(581.10 \mathrm{~mm})$ followed by August (524.18), while the lowest was recorded in February $(1.41 \mathrm{~mm})$ closely followed by December $(1.50 \mathrm{~mm})$. From the analysis, it was observed that rainfall is usually at its peak between June and September which receive over $78 \%$ of the rainfall amount in these months (Table 1).
Table I Statistical analysis of monthly precipitation data (1979-20I0)

\begin{tabular}{lllllll}
\hline Month & PCP_MM & PCPSTD & PCPSKW & $\begin{array}{l}\text { PR } \\
\text { WI }\end{array}$ & $\begin{array}{l}\text { PR } \\
\text { W2 }\end{array}$ & PCPD \\
\hline January & 1.53 & 0.5718 & 17.1128 & 0.0276 & 0.4902 & 1.59 \\
February & 1.42 & 0.3124 & 8.9888 & 0.0359 & 0.4638 & 2.16 \\
March & 17.4 & 2.9232 & 12.3975 & 0.1027 & 0.6947 & 8.19 \\
April & 37.85 & 3.6917 & 6.2742 & 0.186 & 0.7658 & 13.88 \\
May & 113.88 & 5.4781 & 2.5068 & 0.332 & 0.8604 & 23.28 \\
June & 327.11 & 9.6655 & 1.3659 & 0.7917 & 0.9487 & 29.25 \\
July & 581.1 & 11.9267 & 1.6732 & - & 0.9677 & 31 \\
August & 524.18 & 11.2115 & 1.7314 & - & 0.9677 & 31 \\
September & 187.27 & 5.7845 & 2.478 & 0.56 & 0.9508 & 29.22 \\
October & 69.18 & 4.401 & 4.2057 & 0.2261 & 0.8525 & 21.19 \\
November & 11.88 & 1.3132 & 4.6355 & 0.0847 & 0.6711 & 7.13 \\
December & 1.5 & 0.4395 & 12.1876 & 0.0232 & 0.4091 & 1.38 \\
\hline
\end{tabular}

Source: Generated from the precipitation data using PcPSTAT.exe (NMA and GWD for SWAT).

Note: PCP_MM [average monthly precipitation [mm]]; PCPSTD [standard deviation]; PCPSKW [skew coefficient]; PR WI [probability of a wet day following a dry day]; PR_W2 [probability of a wet day following a wet day] and PCPD [average number of days of precipitation in month].

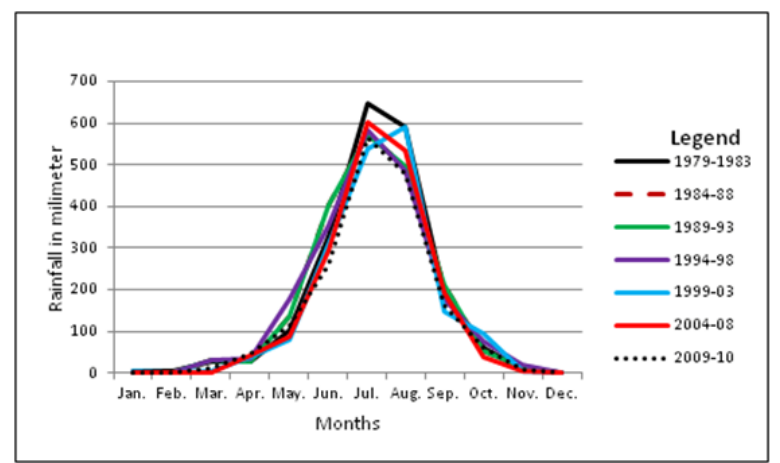

Figure 3 Long-term monthly average rainfall distribution in Denbia woreda $(1979-2010)$.

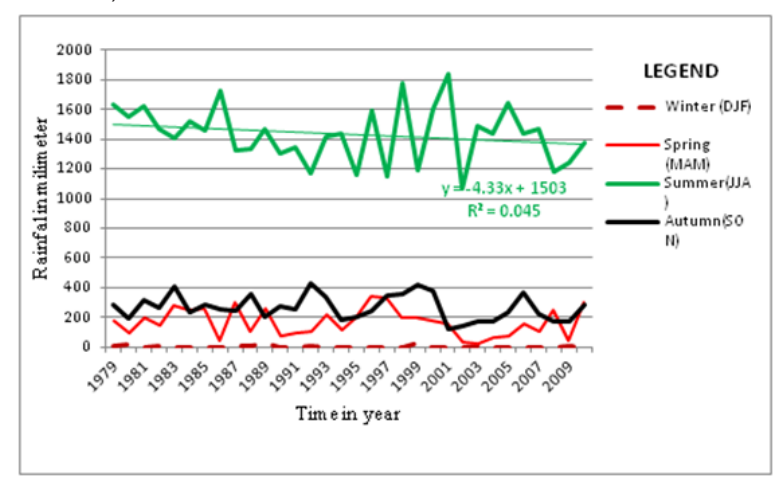

Figure 4 Long-term trends of seasonal rainfall from the year 1979 to 2010. Source: NMA and Global weather data for SWAT [http://globalweather.tamu. edu].

The standard deviation is important to show the spread of a probability distribution across months and years; it relates directly to the degree of uncertainty (insecurity) associated with predicting the value of a random variable. High standard deviation values reflect more uncertainty (insecurity) than low values. When the standard deviation values are examined, it is observed that the values of most months (June, July, and August) are higher than other months (Table 1). The relation between the standard deviation and the average values indicate that deviation from the normal distribution cannot 
be ignored. Figure 3 is used to test whether the annual rainfall data follow a normal distribution. The data set is said to be symmetric if it looks the same to the left and right from the center point. Hence, the annual rainfall distribution under consideration did not follow normal distribution. The simple linear regression results indicate that there is high inter-annual variability of rainfall and slight rate of decline in the woreda over the past decades. Figure 4 clearly shows the total annual precipitation variability across different seasons and years. It is also understandable from the Figure that the total annual rainfall distribution is declining from time to time. However, longterm summer rainfall in the selected time span, appeared to decrease at a non-significant rate $(\mathrm{R} 2=0.045)$. The main problem is the timing (late onset and early cessation) and failing in intense episodes in very short duration. The long-term reduced amount of rainfall calculated using SLR for the observation period indicates that the rainfall declined by $254.39 \mathrm{~mm}$. These results are in line with other empirical research findings conducted in Ethiopia and other nations of Africa. For example, a study in Debark woreda of northwest Ethiopia indicates that the rainfall has shown a decreasing trend. ${ }^{26}$ The study conducted in Tanzania also supported this finding through confirming the decreasing trends of rainfall for the last 35 seasons from 1973/74 to 2007/08. ${ }^{24}$ Similarly, studies in South Africa ${ }^{27}$ and in the Sahel region of $\mathrm{Arica}^{28}$ also found decreasing rainfall tends over the past consecutive decades consistent with the perception of their respective communities (Figure 4). Responses to the questions about whether the household had witnessed changes in precipitation were classified into one of the four different categories: 'increased', 'decreased', 'change in timing/erratic in distribution', and 'no change'. Based on this question, the results of the meteorology data are supported by the perception of the surveyed households. For example, nearly $27 \%$ the households perceived rainfall to be decreasing through time with shorter rainy seasons. Almost $79 \%$ of the households noticed the erratic nature of rainfall-a change in the timing of the rains, coming either earlier or (mostly) later than expected time. Bryan and colleagues (2011) suggest that the farmer's perceptions of long-term decreases in rainfall from the household survey are actually based on their experiences with rainfall variability, and particularly changes in timing and distribution of rainfall.

\section{Drought analysis}

Drought can be manifested by shortage of precipitation that threats the livelihood resources and overall development efforts of nations and specific places through worsening water shortage and damaging agricultural production. Therefore, analysis of drought frequency/ pattern, duration, magnitude and severity is highly demanded for designing appropriate mitigation and adaptation strategies. Standardized precipitation index (SPI) result is presented in Table 3 to characterize long-term drought patterns. It is clear from Table 2 that the rainfall is described by fluctuation of wet and dry years in a periodic pattern. Out of 32years, 15years (46.88\%) recorded below the long-term average annual rainfall amount while $16(53.13 \%)$ years recorded above-average. Only the year 1999 received the same rainfall amount with the long-term average rainfall. Most of the positive SPI values occurred before 1990 ( 9 out of 12 years). Consecutive negative SPI values occurred from 1990 to 1995 and 2002 to 2004. The 2002 rainfall amount was the lowest record in the observation period with SPI value -2.67. According to the drought assessment method, ${ }^{16}$ there were seven drought years in the period spanning from 1979 to 2010 in the site, with varying severity level. There were two extreme (2002) and (2009), one severe drought (1995) and five moderate (1990, 1991, 1992, 1995 and 2008) drought years, which together account for $21.88 \%$ of the total number of observations. In contrast, 1998 was the wettest year in the period followed by the year 1996 (almost consistent with the anomalies of Amhara region identified by Woldeamlak. ${ }^{16}$ This wettest year may be associated with the probability of flood incidences with SPI values of 1.87 and 1.45 in 1998 and 1996 respectively. The SPI result indicates that long-term drought characteristic in the woreda was found to be 12.54-magnitudes and 1.05-intensity in the 12 years of duration indicating very high sensitivity of crops to intense drought conditions similar to agrarian places elsewhere. Similarly, studies in Ethiopia show that the frequency and spatial coverage of droughts have increased over the past few decades..$^{28,29}$ These trends of increasing temperature, decreasing precipitation and the increasing frequency of droughts and floods are predicted to continue in the future in the tropics of Africa where Ethiopia is located. ${ }^{1,29}$ According to the National Meteorological Agency, ${ }^{9}$ Ethiopia experienced 10 wet years and 11 dry years over the last 55 years, demonstrating the strong inter-annual variability. The wet years included 1958, 1961, 1964, 1967, 1968, 1977, 1993, 1996, 1998 and 2006. Dry years were 1952, 1959, 1965, 1972, 1973, 1978, 1984, 1991, 1994, 1999, and 2000.

\section{Perception of households to trend of crop yield stability}

The dominant types of crops grow in the woreda are teff, barley, maize, highland sorghum, millet, bean, peas and chickpeas. They also produce some cash crops like paper, Niger seed, fenugreek, tikurazmud, nechazmud and rice with limited farmlands. Fruit production is not known in there (Menberu 2016). Crop productivity per hectare and trend of crop yield stability in temporal-scale are the most important contexts for measuring livelihood security of the surveyed households. The survey raised questions to the households to give the amount of major crops produced in drought and nondrought conditions. This study also asked questions about the trends of the farmers' major crops yield over the last 20 years or so. The responses were analyzed using descriptive statistics and index of trend of yield (Equation 3) presented in Section 3.3. The interpretation, demonstration, and discussion of the results are addressed in the subsections to come.

Table 2 Standardized Precipitation Index (SPI) for Denbia woreda (19792010)

\begin{tabular}{llllllll}
\hline Year & SPI & Year & SPI & Year & SPI & Year & SPI \\
\hline 1979 & 1.28 & 1987 & 0.14 & 1995 & {$[-1.39]$} & 2003 & {$[-0.73]$} \\
1980 & 0.27 & 1988 & {$[-0.21]$} & 1996 & 1.45 & 2004 & {$[-0.64]$} \\
1981 & 0.71 & 1989 & 0.37 & 1997 & {$[-0.07]$} & 2005 & 0.34 \\
1982 & {$[-0.39]$} & 1990 & {$[-1.21]$} & 1998 & 1.87 & 2006 & 0.59 \\
1983 & 0.73 & 1991 & {$[-1.10]$} & 1999 & {$[-0.01]$} & 2007 & {$[-0.04]$} \\
1984 & 0.54 & 1992 & {$[-0.88]$} & 2000 & 1.22 & 2008 & {$[-0.87]$} \\
1985 & 0.51 & 1993 & {$[-0.50]$} & 2001 & 1.18 & 2009 & {$[-1.79]$} \\
1986 & 0.52 & 1994 & {$[-0.59]$} & 2002 & {$[-2.67]$} & 2010 & 0.35 \\
\hline
\end{tabular}

Source: Global weather data for soil and water assessment tool (SWAT) [http://globalweather.tamu.edu].

\section{Crop productivity in the four kebeles}

The survey results indicate that crop production deviates over space and time due to variation in the quality of farmland, climatic conditions and proximity to sources of flooding besides to other factors. There is considerable variation in the average productivity of cereals, pulses and other major crops from one kebele to another (Table $3)$. It is clear from Table 3 that although it seems underestimated, average crop productivity per hectare is found to be 5.13 quintals in Gerarge, 4.68 in Jenda-kobla, 4.44 in Seraba-dablo, and 2.77 in Tanawoyna kebeles. This is found to be lower than the national average of one tone per hectare for cereals implying how crop production is performing differently in the four kebeles against the national-level 
average crop yield. Table 4 shows the mean variation of crop yields between the four study kebeles of Denbia woreda. The Analysis of one-way Variance (ANOVA) significant at 0.05 level indicate that the mean crop productivity in Gerarge kebele is found to be higher by $0.66,0.7$, and 2.37 quintal than Jenda-kobla, Seraba-dablo and Tana-woyna kebeles respectively. In Jenda-kobla kebele, crop yield is higher by 0.24 quintals than in Seraba-dablo and 1.9 quintals than in Tana-woyna kebeles. The flood prone Serab-dablo and Tana woyna kebeles provided low crop yields consistent with the hazard-ofplace model. ${ }^{30,31}$ The hazard-of-place model noted that a geographic exposure such as site, situation, and proximity to the sources of any hazard and the socio-economic conditions of places such as the ability to respond, to cope up with, to recover from, and to adapt to such hazards influence the hazard potential (Figure 5). Other studies also argue that the parameter of sensitivity is strongly linked to location and is evaluated by the inherent characteristics of places, considering human-environmental relationship, where both social and biophysical characteristics influence this relationship. ${ }^{31,32}$ Places located near the sources of climatic risks continue to suffer more from low rates of economic growth and pervasive poverty. The fragile environment dominated by flood plain site exposed the area to severe flooding and siltation resulting in lamentable agricultural production.

Table 3 The mean variations of crop yield by kebele administration

\begin{tabular}{|c|c|c|c|c|c|c|c|c|}
\hline \multirow[t]{2}{*}{ Kebele } & \multirow[t]{2}{*}{$\mathbf{N}$} & \multirow[t]{2}{*}{ Mean } & \multirow[t]{2}{*}{ Std. Deviation } & \multirow[t]{2}{*}{ Std. Error } & \multicolumn{2}{|c|}{ 95\% Confidence Interval For Mean } & \multirow[t]{2}{*}{ Minimum } & \multirow[t]{2}{*}{ Maximum } \\
\hline & & & & & Lower Bound & Upper Bound & & \\
\hline Gerarge & 44 & 5.1393 & 3.22003 & 0.48544 & 4.1603 & 6.1183 & 1.5 & 19.3 \\
\hline Jenda-kobla & 104 & 4.6817 & 2.45486 & 0.24072 & 4.2043 & 5.1591 & I & 17 \\
\hline Seraba-dablo & 107 & 4.44 & 1.82135 & 0.17608 & 4.0909 & 4.7891 & 1.3 & 13.6 \\
\hline Tana-woyna & 110 & 2.7741 & 1.53937 & 0.14677 & 2.4832 & 3.065 & 0.5 & 10 \\
\hline Total & 385 & 4.0911 & 2.3234 & 0.12161 & 3.852 & 4.3303 & 0.5 & 19.3 \\
\hline
\end{tabular}

Source: Global weather data for soil and water assessment tool (SWAT) [http://globalweather.tamu.edu].

Table 4 Mean difference (ANOVA) of crop yield by kebele administration in Denbia Woreda

\begin{tabular}{|c|c|c|c|c|c|c|}
\hline \multirow[t]{2}{*}{ (I)Kebele name } & \multirow[t]{2}{*}{ (J)Kebele Name } & \multirow[t]{2}{*}{ Mean Difference (I - J) } & \multirow[t]{2}{*}{ Std. Error } & \multirow[t]{2}{*}{ Sig. } & \multicolumn{2}{|c|}{ 95\% Confidence Interval } \\
\hline & & & & & Lower Bound & Upper Bound \\
\hline \multirow[t]{3}{*}{ Gerarge } & Jenda-kobla & 0.45759 & 0.38756 & 0.639 & -0.5427 & 1.4579 \\
\hline & Seraba-dablo & 0.69932 & 0.38594 & 0.269 & -0.02968 & 1.6954 \\
\hline & Tana-woyna & 2.36523 & 0.3844 & 0 & 1.3731 & 3.3574 \\
\hline \multirow[t]{3}{*}{ Jenda-kobla } & Gerarge & -0.45759 & 0.38756 & 0.639 & -1.4579 & 0.5427 \\
\hline & Seraba-dablo & 0.24173 & 0.29674 & 0.848 & -0.5242 & 1.0076 \\
\hline & Tana-woyna & 1.90764 & 0.29474 & 0 & 1.1469 & 2.6684 \\
\hline \multirow[t]{3}{*}{ Sraba-dablo } & Gerarge & -0.69932 & 0.38594 & 0.269 & -1.6954 & 0.2968 \\
\hline & Jenda-kobla & -0.24173 & 0.29647 & 0.848 & -1.0076 & 0.5242 \\
\hline & Tana-woyna & $1.6659 \mid$ & 0.29261 & 0 & 0.9107 & 2.4211 \\
\hline \multirow[t]{3}{*}{ Tana-woyna } & Gerarge & -2.36523 & 0.3844 & 0 & -3.3574 & $-1.373 \mid$ \\
\hline & Jenda-kobla & -1.90764 & 0.29474 & 0 & -2.6684 & -1.1469 \\
\hline & Seraba-dablo & $-1.6659 \mid$ & 0.29261 & 0 & -2.4211 & -0.9107 \\
\hline
\end{tabular}

*The mean difference is significant at 0.05 .

Table 5 Trend of crop yield stability across the four studied kebele administrations

\begin{tabular}{lllll} 
Response Kebele & Increased frequency & Decreased frequency & Constant frequency & Trend of crop yield index \\
\hline Jenda-kobla & 5 & 96 & 5 & -0.86 \\
Seraba-dablo & 15 & 87 & 6 & -0.85 \\
Gerarge & 2 & 41 & 3 & -0.67 \\
Tana-woyna & 8 & 98 & 6 & -0.8 \\
Total/Average & 30 & 322 & 20 & -0.8
\end{tabular}

Table 6 Descriptive and trend analysis of crop yield data for Denbia woreda from 2004 to 2010

\begin{tabular}{llllllll}
\hline Crop type & $\mathbf{N}$ & Minimum & Maximum & Mean & Std. deviation & Correlation coefficient & Trend coefficient \\
\hline Teff & 7 & 8.5 & 18.3 & 15.08 & 3.791 & $0.931^{* *}$ & 1.337 \\
Barley & 7 & 9.9 & 32.4 & 21.33 & 9.083 & $0.870^{*}$ & 2.992 \\
Wheat & 7 & II & 26.5 & 19.1 & 5.24 & $0.927^{* *}$ & 1.84 \\
Millet & 7 & 0.99 & 33.1 & 18.65 & 10.61 & $0.931^{* *}$ & 3.743 \\
Maize & 7 & 24.8 & 52.2 & 35.5 & 10.42 & -0.346 & -1.366 \\
Sorghum & 7 & II & 36.5 & 20.82 & 9.32 & 0.598 & 2.113 \\
Bean & 7 & 8.7 & 50 & 28.58 & 16.2 & 0.807 & 4.954 \\
Pea & 7 & 7.1 & 59.9 & 25.32 & 23.34 & 0.195 & 1.723 \\
\hline
\end{tabular}

**Correlation is significant at the 0.01 level (2-tailed).

*Correlation is significant at the 0.05 level (2-tailed). 


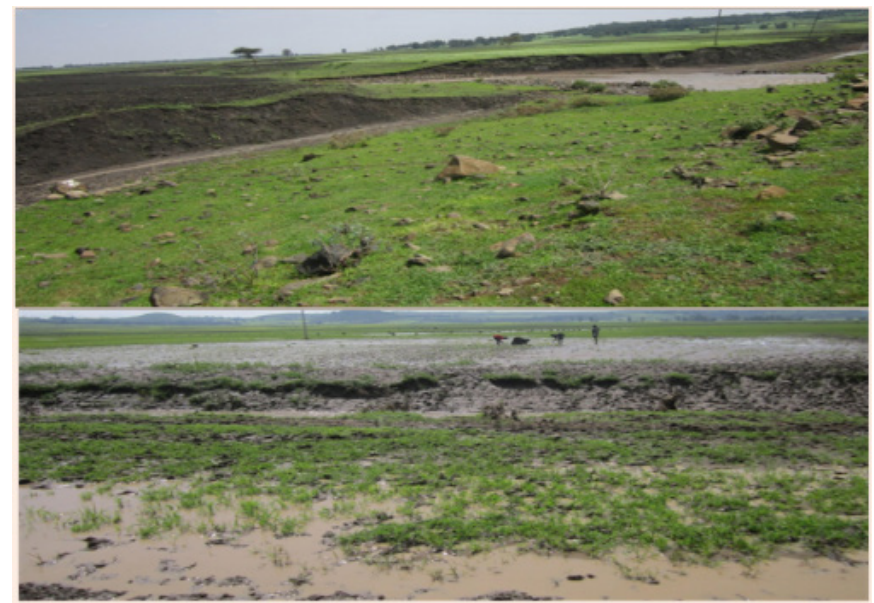

Figure 5 Flood Prone areas in Denbia woreda (Source:Author's field Photo, August 2013).

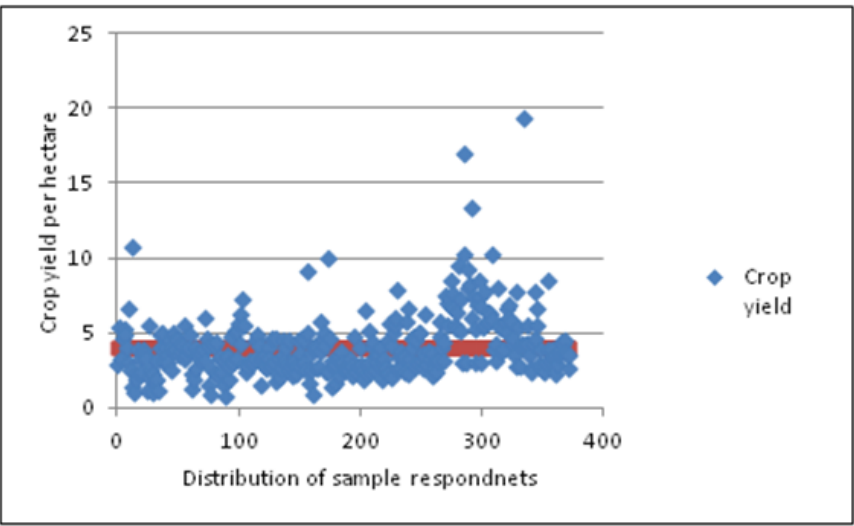

Figure 6 Yield of major crops produced by households against the mean yield.

In the light of the hazard-of-place model ${ }^{33}$ and United Nations Education, Science and Cultural Organization/UNESCO ${ }^{34}$ also underlined that slopes are one of the parameters of the terrain to worsen land degradation. Moreover, the FAO's evaluations have indicated that the target of the World Food Summit to reduce the number of food-insecure persons is not being met and that, despite the signing of major environmental agreements, carbon emissions continue to rise, species extinction is continuing and desertification continues to be of great concern in arid, semiarid and sub-humid areas. ${ }^{33}$ The scatter diagram in Figure 6 demonstrates that the majority of the households are concentrated below or around the mean crop yield of the households. The reasons are attributed to the prevalence of different extreme climatic events such as floods, droughts, soil erosion, pests and diseases. The result is supported by the IPCC ${ }^{1}$ and $\mathrm{NMA}^{9}$ findings which report that the lowest crop yield recorded in the woreda underlining that in the dryer and tropical regions crop productivity is going down even with small local temperature increases $\left(1-2^{\circ} \mathrm{C}\right)$ thereby increasing risk of hunger in those locations. The warmer climatic conditions in the studied woreda are usually more favorable for the proliferation of insect pests. In this line of argument, $\mathrm{FAO}^{5}$ noted that longer growing seasons may enable a number of pest species to complete a greater number of reproductive cycles during the spring, summer, and autumn. Warmer winter temperatures may also allow larvae to winter-over in areas where they are now limited by cold weather conditions, thus causing greater infestation during the coming crop season.

\section{Trends of crop yield stability}

The trends of crop yield stability over the last decades are important contexts to measure households' livelihood vulnerability to climate change-induced risks. In this regard, the rural households were asked whether crop yield has shown improvement for the past 20 years or so. Based on the households' responses, frequencies and percentages for the three responses of increased', 'decreased' and 'no change' were first computed to found out the trend of crop yield stability indices using Equation 3. ${ }^{35}$

It is clear from Table 5 that larger proportion of the households $(86.55 \%)$ reported decreasing crop production pattern since the past 20 years or so. Only $8.1 \%$ of surveyed households observed an increasing trend. The rest $5.37 \%$ of them perceived no change in crop production pattern over the same period. Due to poor rainfall timing coupled with high evapo-transpiration resulting from higher temperatures Denbia is expected to experience huge losses in production of major food crops. The index results presented in Table 5 (fifth column) reveals the negative trend of crop yield in the woreda with an index value of $[-0.80]$, indicating greater crop yield decline since the past 20 years or so in agreement with several previous assessments. ${ }^{36,16,37}$ Relatively slow decline was reported in Gerarge kebele [-0.67], which is situated far away from sources of flooding and severe soil degradation than other kebeles. Crop yield stability indices in other kebeles range from [-80] in Tana-woyna to [-0.86] in Jenda-kobla. However, this finding identified the contradictory findings between official agricultural statistics and households' responses to crop yields.

\section{Crop yield trend analysis using official records}

To see whether crop yield trend is consistent with households' perceptions the crop yield data gathered from North Gondar Zone Agriculture Department Office from 2004 to 2010 were processed and analyzed (Table 6). Table 6 presents the descriptive and trend analysis of crop yield data for Denbia woreda from 2004 to $2010 .{ }^{38}$ It is clear from the Table that Teff, barley, wheat, millet, sorghum, bean and pea yield show increasing tendency with a trend coefficient of 1.3373, $2.992,1.840,3.743,2.113,4.9545$ and 1.723 quintals per hectare per year respectively in contrary to households' perception while maize yield show a decreasing tendency with a trend coefficient of 1.366 quintals per hectare per year consistent with household' perception. In statistical terms, teff, barley, wheat and millet yield trends are significant at $1 \%$ and $5 \%$ while trend of maize, sorghum, bean and pea are not statistically significant. Out of all crops studied, teff has the lowest mean yield of 15.1 quintals per hectare while maize has the highest mean yield of 35.5 quintals per hectare for the woreda (Table 6). The maximum yields (in Quintal per hectare) for teff (18.0), barley (32.4), wheat (26.5), millet (33.1), maize (52.2), sorghum (36.5), bean (50.0) and pea (59.9) were recorded in different years while the minimum values for teff yield (8.5), barley (9.9), wheat (11.0), millet (0.99), maize (24.8), sorghum (11.0), bean(8.7) and pea(7.1) were recorded in 2004 for all crops except for maize which was recorded in 2007. The official agricultural data for peas, maize, bean and even barley, sorghum, wheat were found to be exaggerated and against the surveyed households' report. Some scholars related the effectiveness of new technology packages (at least partially) in boosting crop production with good weather conditions. ${ }^{37}$ They also argue that rather than technology adoption, the major factor behind the growth of total production in Ethiopia is expansion of cultivated land area implying further research in the study area. ${ }^{39-41}$ 


\section{Conclusion}

This study investigated the perceived impact of climate change on crop yield trend in Denbia woreda of Amhara Region, Northwest Ethiopia. The results suggest that recent climate trends have had a discernible negative impact on the production of several major crops. The meteorology data reveal that Denbia woreda is found to be increasingly vulnerable to the risks of climate change and associated extreme weather events. Annual temperature in the study area was in increasing trend for the last three decades (1979 to 2010). The rainfall of the woreda is characterized by greater inter-seasonal variability in line with several empirical research findings conducted in Ethiopia and other African countries. The rainfall is also described by alteration of wet and dry years in a periodic pattern over the past 32years. The survey results indicate that larger proportion of the households reported decreasing crop production pattern since the past 20years or so. Similarly, trend of crop yields stability indices revealed the negative trend in the woreda with an index value of $(-0.81)$, indicating very high crop yield decline since the past 20 years or so in the study area. The flood exposed Tana-woyna kebele followed by Seraba-dablo provided very low crop yield consistent with the hazard-of-place model, which notes that geographic exposure to the sources of hazard influence the hazard potential. The parameter of sensitivity is strongly linked to location and is evaluated by the inherent characteristics of places, considering human-environmental relationship. Places located near the sources of climatic risks continue to suffer from low rates of economic growth and pervasive poverty. On the contrary, households mainly reside in Gerarge kebele reported relatively slow crop yield decline because it is situated far away from sources of flash floods and severe soil erosion as compared with other kebele administrations. ${ }^{42,43}$

Based on the findings of this study it can be concluded that context specific adjustments against the adverse effects of climate change and associated extreme climatic events need to be fundamental concern to governmental and non-governmental organizations through increasing resilience capacity of rural households. Local leaders should enforce green laws by encouraging peoples' tree plantation that enable to regulate the local climate through increasing carbon sequestration and reducing flood risks of heavy rainfall events. In this regard, research should be conducted on the reproduction of heat and flood-tolerant crops in the study area. Moreover, although official agricultural statistics heralded fast growth in yield and total agricultural production over the past years in Denbia woreda, the households reported the contrary, decreasing crop production trend. Therefore, further research is needed in order to settle the contradictory reports by official yield statistics and rural households' perceptions on crop yield trend over the past years.

\section{Acknowledgments}

The author wishes to thank the farmers for their cooperation, the enumerators who patiently carried out the household surveys, the experts at Denbia woreda district office of agriculture, and development agents (DAs) at the specific study sites. This study was supported financially by University of Gondar.

\section{Ethics Approval and Consent to Participate}

Not applicable by the university. Only researches on heath are obliged to have ethical clearance.

\section{Consent for publication}

+Not applicable in this section.

\section{Availability of data and materials}

Global weather data for SWAT [https://globalweather.tamu.edu/].44 This website allows you to download daily CFSR data (precipitation, wind, relative humidity, and solar) in SWAT file format for a given location and time period free.

\section{Author's contributions}

MT has made substantial contributions in designing the research, acquisition of the necessary data, interpretation of results and leading the research activities. He has given also the final approval of the version to be published.

\section{Conflicts of interest}

The author declares that there are no conflicting interests forms University of Gondar (Funding body).

\section{Funding}

The funding body, University of Gondar, had no any role in the design of the study and collection, analysis, and interpretation of data and in writing the manuscript.

\section{References}

1. IPPC/Intergovernmental Panel on Climate Change. Adaptation to Climate change in the context of sustainable development, background paper. Bonn, UNFCCC Secretariat, Germany; 2007.

2. IPCC/Intergovernmental Panel on Climate Change. Intergovernmental panel on climate change 2001: Impacts, adaptation and vulnerability. Cambridge: Cambridge University Press, USA; 2001.

3. Schipper EL. Exploring Adaptation to Climate Chnage: A Development Perspective. East Angelia: East Angelia University Press, UEA; 2004.

4. World Bank. The economics of adaptation to climate change. New York: International Bank for Reconstruction and Development. 2008.

5. FAO/Food and Agricultural Organization. Coping with a changing climate: considerations for adaptation and mitigation in agriculture. Food and Agricultural Organization/FAO, Rome; 2009.

6. Philip A, Augustine Yelfaanibe, Abindaw Bernard A. Impact of climate variability on small holder households and indigenous coping strategies in Bonga District. Int J Develop Res. 2014;4(3):693-699.

7. Falaki AA, Akangbe JA, Ayinde OE. Analysis of climate change and rural farmers' perception in North Central Nigeria. J Hum Ecol. 2013;43(2):133-140.

8. Cline WR. Global warming and agriculture: impact estimates by country. Center for Global Development, Washington, DC, USA; 2007.

9. NMA/National Meteorological Agency. Climate change National adaptation program of action (NAPA) of Ethiopia. Addis Ababa: NMA, Ethiopia; 2007.

10. Girma M, Fekadu G. Climate change projections for Ethiopia. Addis Ababa: Ethiopian journal of agricultural science; 2010

11. CDC/Center for Disease Control and Prevention. A report on inventory and pre-inventory at sixty four woredas in Amhara Region. Bahir Dar, Ethiopia; 2008.

12. Melesse Y. Challenges of livelihood and food security in enebsiesairmirder woreda of the Amhara National Regional State, Ethiopia. M.A thesis, Addis Ababa University, Ethiopia; 2007.

13. Marye B. Local peoples perception on climate change, its impacts and adaptation measures in Simada Woreda of South Gondar. MA Thesis, Addis Ababa University, Ethiopia; 2011 
14. Denbia Woreda Office of Agriculture. Unpublished Annual Report, Koladiba, Denbia, Ethiopia; 2013

15. Yesuf $\mathrm{M}$, Difalco $\mathrm{S}$, Ringler $\mathrm{C}$, et al. Impacts of climate change and adaptation to climate change on food production in low income countries: Household survey data: evidence from the National Bureau of Ethiopia. Washington DC: IFPRIC discussion paper, Ethiopia; 2008.

16. Woldamelak B. Mainstreaming climate change adaptation into project planning and progrmme, a paper submitted to Norwegian Church id -Ethiopia. Addis ababa; 2009.

17. World Vision Ethiopia. Denbia Area development program document, programme number: 00558, phase number of the program: (2008-2012, Phase I), Bahir Dar, Ethiopia; 2007.

18. Menberu T. Farmers' vulnerability to climate change-induced water poverty in spatially different agro-ecological areas of Northwest Ethiopia. Journal of Water and Climate Change, in Press, IWA Publishing, Ethiopia; 2015.

19. Menberu T. Rural households' agricultural land vulnerability to climate change in Denbia woreda, Northwest Ethiopia. Environmental Systems Research Journal. 2016;5(14).

20. Israel GD. Determining Sample Size. IFAS Extension, University of Florida; 1992:1-7.

21. McKee TB, Doesken NJ, Kleist J. The relationship of drought frequency and duration to time scales. Eighth Conference on Applied Climatology. Anaheim, California: Colorado State University, USA; 1993:1-6.

22. Ahmad R, Qadir S, Ahmad N, et al. Yield potential and stability of nine wheat varieties under water stress conditions. International Journal of Agriculture and Biology. 2003:1560-8530.

23. McSweeney C, New M, Lixcano G. Ethiopia-UNDP Climate change country profiles. A preliminary assessment of characteristics and longterm variability of rainfall in Ethiopia-basis for sustainable land use and resource management. In Conference in International Agricultural Research. New York, USA; 2007.

24. Mongi H, Majule AE, Lyimo J. Vulnerability and adaptation of rain-fed agriculture to climate change and variability in semi-arid Tanzania. African Journal of Environmental Scence and Technololgy. 2010;4(6):371-381.

25. Doering OC, Randolph JC, Southworth J, et al. Effects of climate change and variability on agricultural production systems. Kluwer Academic Publishers, Dordrecht, Netherlands; 2002.

26. ACCRA/African Climate Change Resilience Alliance. Understanding the influence of development interventions on adaptive capacity at Local Level in Ethiopia, Africa Climate Change Resilience Alliance (ACCRA) Ethiopia Synthesis Report. Addis Ababa: Africa Climate Change Resilience Alliance (ACCRA), Ethiopia; 2011.

27. Gbetibouo GA. Understanding farmers' perceptions and adaptations to climate change and variability: The case of Limpopo basin, South Africa; 2009.

28. Mertez O, Mbow C, Reenberg A, et al. Farmers' Perceptions of Climate Change and Agricultural Adaptation Strategies in Rural Sahel. Environmental Management. 2008;43(5):804-816.
29. Lautze S, Aklilu Y, Raven-Roberts A, et al. Risk and vulnerability in ethiopia: learning from the past, responding to the present, preparing for the future. Report for the U.S. Agency for International Development. Addis Ababa, Ethiopia; 2003.

30. Temesgen T. Assessment of the vulnerability of Ethiopian agriculture to climate change and farmers' adaptation strategies, University of Pretoria, South Africa; 2010.

31. Cutter SL, Boruff BJ, Shirley WL. Social vulnerability to environmental hazards. Social Science Quarterly, Volume 84(2), Southwestern Social Science Association 2003;84(2):242-262.

32. Gallopin GC. Linkages between Vulnerability, Resilience, and Adaptive Capacity. Global Environmental Change. 2006;16(3):293-303.

33. Turner II, BL Kasperson, RE Matsone, et al. A framework for vulnerability analysis in sustainability science. PNAS. 2003;100(14):8074-8079.

34. FAO/Food and Agricultural Organization. Integrated natural resources management to enhance food security: the case for community-baesd approaches in Ethiopia. Rome: FAO, Ethiopia; 2003.

35. UNESCO/United Nations Educational, Scientific, and Cultural Organization. National Water Development Report (Final), World Water Assessment Program. Addis Ababa: Ministry of Water Resources and UNESCO; 2004.

36. Rasul G, Thapa GB. Sustainability analysis of ecological and conventional agricultural systems in Bangladesh. World Development. 2003;31(10):1721-1741.

37. Lobell D, Field C. Global scale climate-crop yield relationships and the impacts of recent warming. Public Health Resources. Paper 152, USA 2007.

38. Denbia Woreda Administration Office. Unpublished Population Statistics, Koladiba, Denbia, Ethiopia; 2014.

39. Taffesse A, Dorosh P, Asrat S. Crop production in Ethiopia: Regional patterns and trends, Ethiopia strategy support program II (ESSP II). Addis Ababa and Washington DC: International Food Policy Research Institute; 2011.

40. Feige S, Marr MA. Sampling manual: A guide to sampling under the CDM with special focus to POAs, 1st edn. Frankfurt: KfW, Germany; 2012.

41. Maddison D. The perception of and adaptation to climate change in Africa. CEEPA Discussion Paper No. 10. Centre for Environmental Economics and Policy in Africa, University of Pretoria, South Africa; 2006.

42. Temesgen T. Measuring Ethiopian farmers vulnerability to climate change across Regional States. Addis Ababa: IFPRI, Ethiopia; 2006.

43. Vedwan N, RE Rhoades. Climate change in the Western Himalayas of India: a study of local perception and response. Climate Research. 2001;19:109-117.

44. Global weather data for SWAT (1979-2010), USA. 